\title{
Retracted: Optimum Rotation Speed for the Friction Stir Welding of Pure Copper
}

\author{
International Scholarly Research Notices \\ Received 9 July 2014; Accepted 9 July 2014; Published 29 October 2014 \\ Copyright (C) 2014 International Scholarly Research Notices. This is an open access article distributed under the Creative Commons \\ Attribution License, which permits unrestricted use, distribution, and reproduction in any medium, provided the original work is \\ properly cited.
}

This paper [1] has been retracted as it is essentially identical in content with the published article "Elucidating of rotation speed in friction stir welding of pure copper: Thermal modeling" published in Computational Materials Science, Volume 81, January 2014, Pages 296-302.

\section{References}

[1] M. Jabbari and C. C. Tutum, "Optimum rotation speed for the friction stir welding of pure copper," ISRN Materials Science, vol. 2013, Article ID 978031, 5 pages, 2013. 


\title{
Optimum Rotation Speed for the Friction Stir
} Welding of Pure Copper

\author{
Masoud Jabbari ${ }^{1}$ and Cem C. Tutum ${ }^{2}$ \\ ${ }^{1}$ Department of Mechanical Engineering, Technical University of Denmark, Nils Koppels Allé, 2800 Kongens Lyngby, Denmark \\ ${ }^{2}$ Department of Computer and Electrical Engineering, Michigan State University, East Lansing, MI 48824, USA
}

Correspondence should be addressed to Masoud Jabbari; mjab@mek.dtu.dk

Received 24 June 2013; Accepted 14 July 2013

Academic Editors: S. Kirihara and S. Li

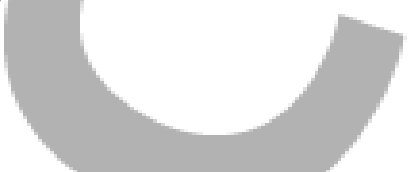

Copyright ( 2013 M. Jabbari and C. C. Tutum. This is an open access article distributed under the Creative Commons Attribution License, which permits unrestricted use, distribution, and reproduction in any medium, provided the original work is properly cited.

The friction stir welding (FSW) was conducted in the pure copper plates with the thickness of $4 \mathrm{~mm}$ in the constant traverse speed of $25 \mathrm{~mm} / \mathrm{min}$ and five different rotation speeds. Analysis of metallographic images showed that the increasing of the rotation speed results in the increase of grain size in the nugget zone. Vickers hardness tests were conducted on the weld samples and the maximum hardness obtained in rotation speed of $900 \mathrm{rpm}$. Results of the tensile tests and their comparison with that of the base metal showed that the maximum strength and the minimum elongation are achieved again in this rotation speed. Yield strength and ultimate tensile strength increased with the decrease in grain size in the nugget region, and the yield strength obeyed $\sigma_{s}=172.77+59.33 d^{-1 / 2}$ Hall-Petch relationship. Hence, the hardness values do not follow the relationship.

\section{Introduction}

The friction stir welding (FSW) was invented by The Welding Institute, UK, in 1991 for primarily welding of aluminum alloys [2]. In FSW process, a nonconsumable rotating cylindrical shouldered tool with a smaller pin is plunged into adjoining parent materials. Frictional heat generated by the tool shoulder causes the work piece materials to soften $[3,4]$. Moreover, FSW involves a severe plastic deformation (SPD) and dynamic recrystallization (DRX) in the nugget zone due to the stirring action of the tool pin [5]. Extensive studies on FSW of aluminum and its alloys have been reported in the literature; however, studies on copper are very limited. This limitation is due to the fact that the high melting point and the high heat conductivity of copper necessitate a higher heat input to obtain a defect-free copper weld. Although copper has a faced-centered cubic structure (FCC) and a good ductility, obtaining sound weld is more difficult than using aluminum and the magnesium alloys $[1,6]$. FSW of the copper must be conducted in lower welding speed or in higher rotation speed to increase the heat input during the process. Furthermore, not much has been published concerning the details of the metallurgical and mechanical properties of the welds. Moreover, it has been shown that there were many mismatched results in the mechanical properties in the welds [7].

The effect of the tool rotation speed plays an important role in the amount of the total heat input applied during the process; however, this phenomenon is mostly analyzed qualitatively, and the conclusions have been made based on the resultant weld defects. Therefore, the optimum range of the rotation speed will be an important parameter to achieve high quality weld, since the variation of this parameter will affect the thermomechanical condition for the microstructural changes in the specimen. This optimum range is affected by different parameters such as the thickness of work piece, type of alloy, geometry of the tool, and welding speed.

Xue et al. [8] investigated FSW of the copper plates with the thickness of $5 \mathrm{~mm}$ in the $1 / 2 \mathrm{H}$ condition. They conducted two different experimental tests, that is, one in the constant traverse speed of $50 \mathrm{~mm} / \mathrm{min}$ with different rotation speed of 400,600 , and $800 \mathrm{rpm}$ and the other with the constant rotation speed of $800 \mathrm{rpm}$ and different traverse speeds of 50 , 100 , and $200 \mathrm{~mm} / \mathrm{min}$. Their results showed that increasing 
TABLE 1: Chemical composition of the pure copper plates.

\begin{tabular}{lcccccccc}
\hline $\mathrm{Cu}$ & $\mathrm{Ni}$ & $\mathrm{Zn}$ & $\mathrm{Si}$ & $\mathrm{Al}$ & $\mathrm{Fe}$ & $\mathrm{Mn}$ & $\mathrm{B}$ & $\mathrm{Sb}$ \\
\hline 99.85 & 0.08 & 0.041 & 0.007 & 0.006 & 0.006 & 0.006 & 0.002 & 0.001 \\
\hline
\end{tabular}

the rotation speed as well as decreasing the traverse speed results in the increase of the heat input, and consequently it will increase the grain size of the nugget zone.

Xie et al. [1] also conducted FSW of the copper plates with the thickness of $5 \mathrm{~mm}$ under the $1 / 2 \mathrm{H}$ condition and constant welding speed of $50 \mathrm{~mm} / \mathrm{min}$ and different rotation speeds of 400, 600, and $800 \mathrm{rpm}$. They reported that defectfree copper welds were achieved under relatively low heat input conditions with a fine-grained microstructure of 3.5$9 \mu \mathrm{m}$ being produced at a rotation speed of $400 \mathrm{rpm}$ for a traverse speed of $50 \mathrm{~mm} / \mathrm{min}$. They also mentioned that there is a correlation between the grain size and the mechanical properties, that is, the Hall-Petch relationship. However, the samples with coarse-grained copper did not fit the Hall-Petch relationship.

Lee et al. [4] performed FSW on the copper plates of $4 \mathrm{~mm}$ thickness with the traverse speed of $61 \mathrm{~mm} / \mathrm{min}$ and the rotation speed of $1250 \mathrm{rpm}$. Although they obtained fine grain structure in the nugget zone as compared to base metal, the hardness of the nugget zone was less than that of the base metal. They reported that the hardness distribution in the welded samples does not obey the Hall-Patch law, and moreover the other factors such as the second phase and the dislocation density contributed to the hardness of weld.

Apart from the traverse and the rotation speeds, the thickness of the samples is also important. As the thickness decreases the local heat generation in the specific volume increases resulting in more heat input to the sample. This causes more softening of material and increasing in the grain size. It should be kept in mind that for smaller values of the thickness the process parameters should be fixed in order to get lower heat input. This might be the reason why in the work conducted by Lee et al. [4] the hardness values in the weld zone are lower than that of the base metal.

The aim of this paper is to study the effect of the rotation speed on the microstructure and mechanical properties of the pure copper plates of $4 \mathrm{~mm}$ thickness. A constant traverse welding speed of $25 \mathrm{~mm} / \mathrm{min}$ has been used. Based on this investigation, the optimum rotation speed is proposed.

\section{Experimental Procedure}

Table 1 shows the chemical composition of the copper plates with the dimensions of $200 \times 75 \times 4 \mathrm{~mm}^{3}$. These plates were in the as-rolled condition, and they were annealed at $400^{\circ} \mathrm{C}$ for 2 hours before welding.

A CNC milling machine was used to perform the FS welds. Table 2 shows the geometrical properties of the welding tool used in this experiment. The copper plates were clamped rigidly on the steel backup plate to support torsion applied by the rotating FSW tool and the deformations due to residual stresses built up during the process.

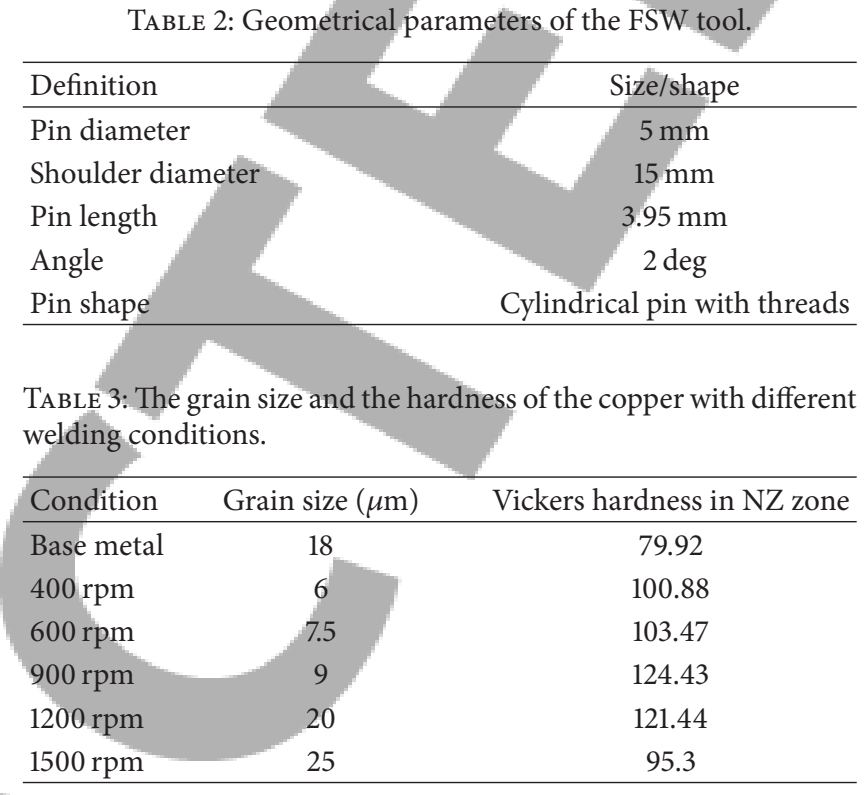

The rotating pin was plunged into the joint line of the plates, and the dwell period took 15 seconds. Then, welding was carried out in constant traverse speed of $25 \mathrm{~mm} / \mathrm{min}$ with different rotation speeds of 400, 600, 900, 1200, and $1500 \mathrm{rpm}$.

Following the visual inspection of the welded samples (i.e., just looking at the weld quality), microstructural characterization was carried out by the optical microscopy. The metallographic samples were cut at a section perpendicular to the welding direction in the middle of the joints. After polishing, they were etched in the aqueous solution having $15 \mathrm{~mL}$ hydrochloric acid $(\mathrm{HCl}), 100 \mathrm{~mL}$ distilled water, and 2.5 gr iron chloride. The average grain size in the base metal and the nugget zone of each sample was measured by the linear intercept method. Vickers hardness measurements were performed at the mid thickness of the cross-section of the welded plates with $100 \mathrm{gr}$ of load and ten seconds of dwell time. Tensile tests were carried out using a universal tensile test machine at a cross-head speed of $2 \mathrm{~mm} / \mathrm{min}$.

\section{Results and Discussion}

3.1. Microstructural Characterization. Defect free welds were achieved considering the wide range of rotational speeds (i.e., 400 to $1500 \mathrm{rpm}$ ) at the constant traverse speed of $25 \mathrm{~mm} / \mathrm{min}$. Based on the microstructural characterization, four distinct zones are identified in the FSW joints: the nugget zone (NZ), the thermomechanical affected zone (TMAZ), the heat affected zone (HAZ), and the base metal. Figure 1 represents the microstructure of NZ with different rotation speeds. As it is seen from Figure 1, the grain size in the NZ increases while increasing the rotation speed from 400 to $1500 \mathrm{rpm}$. 


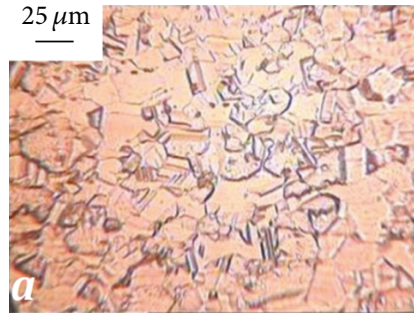

(a)

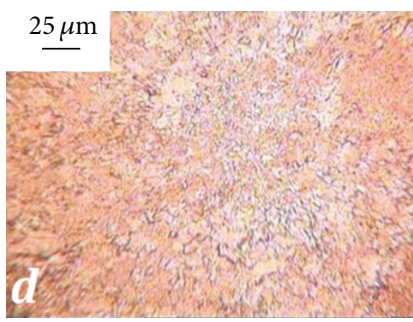

(d)

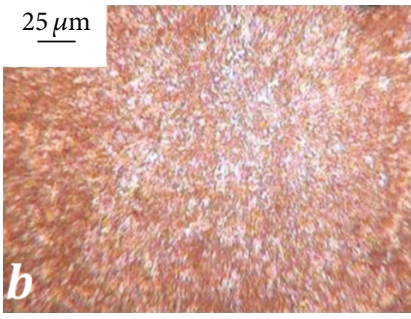

(b)

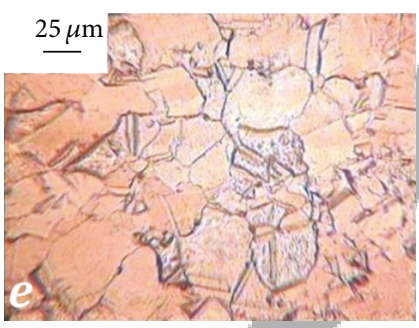

(e)



(c)



(f)

FIGURE 1: Microstructure of the NZ for (a) base metal and for rotation speeds of (b) 400, (c) 600, (d) 900, (e) 1200, and (f) $1500 \mathrm{rpm}$.

It can be seen that for the first three welds (those welded with rotational speeds of 400,600 , and $900 \mathrm{rpm}$ ) NZ has finer microstructure as compared to the base metal.

The variation of the average grain size in the NZ with the rotation speed is summarized in Table 3 . At temperatures approximately $(0.3-0.5) T_{m}$ (i.e., $T_{m}$ is the melting temperature of the metal), the recovery and the recrystallization occur because of the plastic deformation and the resultant heat. These phenomena are called as the dynamic recovery and the dynamic recrystallization (DRX), respectively, in which they have the key roles on the microstructure development of the joint parts produced by the FSW. The strain in the work piece during FSW is affected by the weld pitch (the displacement of the pin in the travel direction for one rotation of the tool), the number of threads per inch, and the thread depth. Because of the high strain rates as well as strains associated with the FSW process, considerable energy is stored in the weld, and this can be released only by the nucleation and the growth of the new strain free grains. The release of the energy and the resultant reduction of the average grain sizes during the welding are due to the dynamic recrystallization. According to the general principles of the recrystallization, an increase of the rotation speed (with a constant traverse speed) results in an increase in both the degree of deformation and the peak temperature of process (i.e., a decrease of the recrystallization temperature) and vice versa. Therefore, the increase in the degree of deformation results in the decrease in the recrystallized grain size. On other hand, an increase in the peak temperature leads to generation of coarser recrystallized grains. Consequently, the variation of the recrystallized grain size with rotation speed in the FSW process depends on the domination of the mentioned parameters. In this study, the degree of deformation is found to be the dominant factor at the beginning of the process, and with the further increase of rotation speed, the peak

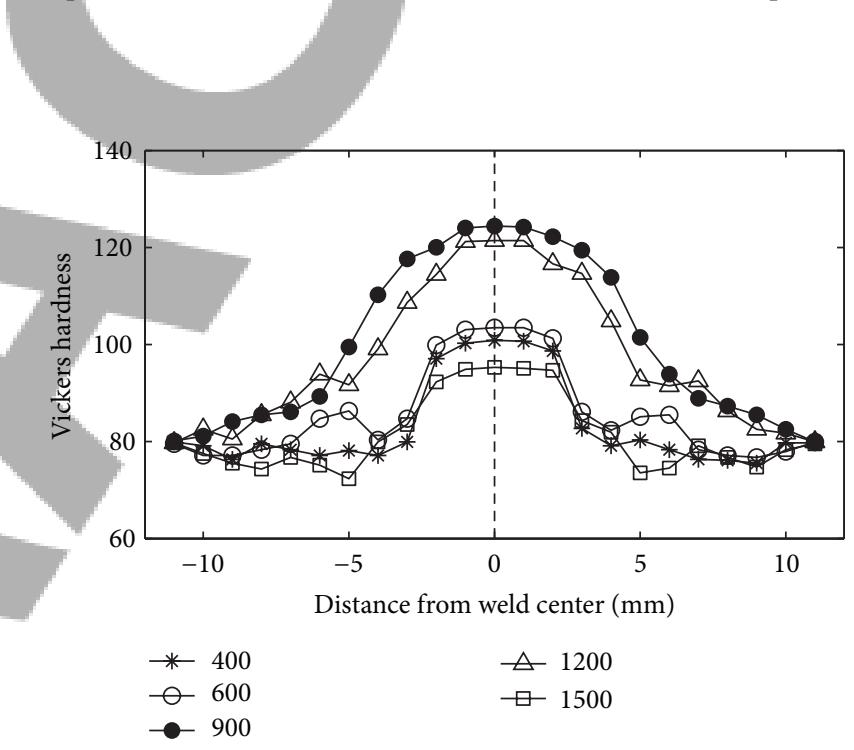

Figure 2: The hardness distribution in the transverse direction of the welds for different rotation speeds.

temperature during FSW becomes the dominant factor. As a result, low rotation speeds of 400,600 , and $900 \mathrm{rpm}$ result in finer microstructure and higher rotation speeds above $900 \mathrm{rpm}$ up to $1500 \mathrm{rpm}$ result in coarser microstructure.

3.2. Hardness Evaluation. The hardness profiles in the transverse direction of the welds for different rotation speeds are illustrated in Figure 2. According to this figure, the following important observations were made.

(1) The maximum hardness is obtained in the nugget zone for all sample tests.

(2) The hardness of all the samples in the nugget zone is higher than that of the base metal. 


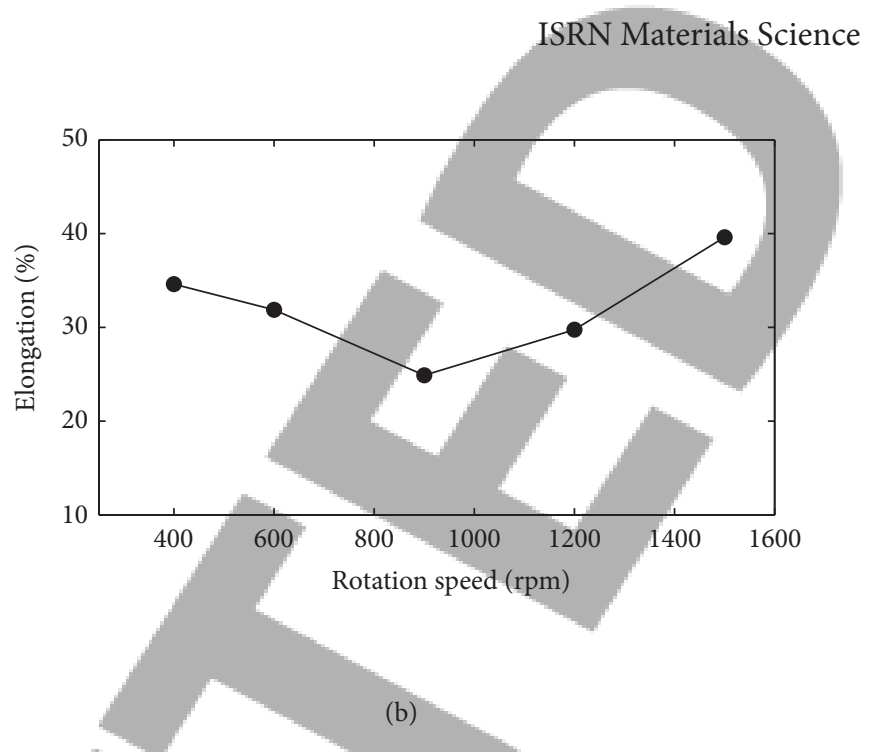

(a)

FIGURE 3: Tensile properties of the copper joints with different rotation speeds: (a) tensile and yield strength and (b) elongation.

(3) The samples welded with the rotation speeds of 900 , $1200,600,400$, and $1500 \mathrm{rpm}$ show the maximum to minimum hardness in the nugget zone, respectively.

(4) The hardness in the retreating side (the right-hand side of the sash line) is a bit higher than that of the advancing side (the left-hand side of the sash line) of the weld.

Although the grain size of the NZ is greater than that of the base metal in the range of rotation speed above $900 \mathrm{rpm}$, the hardness of the nugget zone is greater than that of the base metal, which means that the hardness does not correlate with the grain size in this particular range of rotation speed (see Table 3). Hence, these results indicate that the hardness distribution in the NZ does not follow the Hall-Petch relation. The Hall-Petch relation would be valid if grains were dislocation free. Therefore, it can be argued that the other factors should affect the microstructure properties of the nugget zone such as subboundaries, subgrains, dislocations, and second phases [1, 9-12].

As already mentioned, the increase of the rotation speed and the degree of deformation resulted in the increase of dislocation densities in recrystallized grains. With a further increase of the rotation speed, the temperature increases and the recrystallized grains are annealed, and as a result the hardness decreases. Further increase in the rotation rate from 1200 to $1500 \mathrm{rpm}$ caused the annealing mechanism to be more dominant, and as a consequence the hardness was decreased. The lowest hardness values on the advancing side were generally lower than those lowest values on the retreating side. This can be attributed to a higher temperature on the advancing side which is well known for the FSW process [2].

3.3. Tensile Characterization. Figures 3(a) and 3(b) show the transverse tensile properties (the strength and the elongation, resp.) of the joints welded at different rotation speeds. The transverse tensile specimens contained microstructures from all four zones, that is, NZ, TMAZ, HAZ, and BM.
Therefore, strength of specimens would be average strength of presence zones. According to Figure 3(a), the yield strength of specimens was increased with increasing of rotation speed up to $900 \mathrm{rpm}$ and then decreased with a further increase of rotation speed. However, tensile strength of specimens with increasing of rotation speed to $1200 \mathrm{rpm}$ showed a little variation. In the FSW joints, the HAZ and the TMAZ are critical zones so that, these zones often have the minimum hardness, and fracture initiates from these regions $[2,8,13]$. A sudden change in the hardness can also result in weakening of these zones, and fracture occurs. When the hardness of NZ is the highest, therefore the joint will most likely fracture in the lower hardness zones, that is, TMAZ, HAZ, and BM. As the results of the hardness showed previously, samples welded with rotation speeds of 400,600, 1200, and $1500 \mathrm{rpm}$ have the minimum hardness in the HAZ or TMAZ, and samples welded with rotation speed of $900 \mathrm{rpm}$ have the minimum hardness in the BM. It should be noted that copper has a face centered cubic (FCC) lattice structure, and usually the cleavage fracture does not occur in the FCC materials. However, it may occur in the result of low temperature conditions and in the presence of material defects.

The correlation between the grain size and the yield strength obtained from the preset study is illustrated in Figure 4. The Hall-Petch relationship proposed by Xie et al. [1] (solid line) is also presented in Figure 4. They claimed that the aforementioned correlation does follow the Hall-Petch relationship as follows:

$$
\sigma_{s}=36.2+170 d^{-1 / 2}
$$

However, for the present study the Hall-Petch relationship is obtained as follows:

$$
\sigma_{s}=172.77+59.33 d^{-1 / 2}
$$

\section{Conclusions}

Friction stir welding was conducted on pure copper alloy, and the effect of different rotation speed was evaluated. 


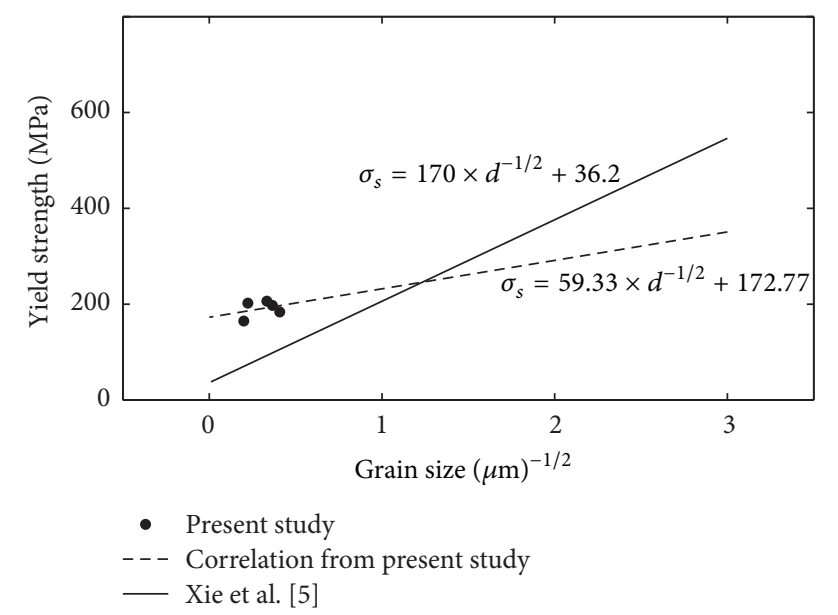

FIGURE 4: The correlation between the grain size and the yield strength from present study and the comparison with Xie et al. [1].

Microstructural and mechanical tests were used to characterize the influence of varying rotation speeds. The results of investigation are summarized as follows.

(1) Defect free welds are achieved in rotational speed range of 400-1500 rpm.

(2) In low rotation speed, the grain size of the NZ is smaller as compared to that of the base metal. However, by further increasing of the rotation speed, the grain size increases due to the higher values of the heat input.

(3) Although in rotation speed above $900 \mathrm{rpm}$ grain size of the NZ is greater than that of base metal, the hardness of this zone is greater than that of base metal. This means that the hardness of the NZ mainly depends on the density of dislocation rather than the grain size.

(4) With increasing the rotation speed at the constant traverse speed, the tensile strength increases, and then decreases with the peak value in the rotation speed of $900 \mathrm{rpm}$. The yield strength does not change so much in the beginning and then decreases in the higher rotational speed, however the elongation decreases at first and then increases.

(5) The yield stress of the weld joints does follow the HallPetch relation as $\sigma_{s}=172.77+59.33 d^{-1 / 2}$.

\section{References}

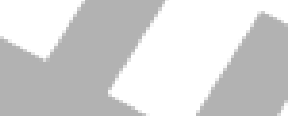

[1] G. M. Xie, Z. Y. Ma, and L. Geng, "Development of a finegrained microstructure and the properties of a nugget zone in friction stir welded pure copper," Scripta Materialia, vol. 57, no. 2, pp. 73-76, 2007.

[2] R. S. Mishra and Z. Y. Ma, "Friction stir welding and processing," Materials Science and Engineering $R$, vol. 50, no. 1-2, pp. 1-78, 2005.

[3] A. Polar and J. E. Indacochea, "Microstructural assessment of copper friction stir welds," Journal of Manufacturing Science and Engineering, vol. 131, no. 3, pp. 0310121-0310127, 2009.
[4] W. Lee and S. Jung, "The joint properties of copper by friction stir welding," Materials Letters, vol. 58, no. 6, pp. 1041-1046, 2004.

[5] M. W. Mahoney, C. G. Rhodes, J. G. Flintoff, R. A. Spurling, and W. H. Bingel, "Properties of friction-stir-welded 7075 T651 aluminum," Metallurgical and Materials Transactions A, vol. 29, no. 7, pp. 1955-1964, 1998.

[6] C. G. Rhodes, M. W. Mahoney, W. H. Bingel, R. A. Spurling, and C. C. Bampton, "Effects of friction stir welding on microstructure of 7075 aluminum," Scripta Materialia, vol. 36, no. 1, pp. 69-75, 1997.

[7] G. Liu, L. E. Murr, C.-S. Niou, J. C. McClure, and F. R. Vega, "Microstructural aspects of the friction-stir welding of 6061-T6 aluminum," Scripta Materialia, vol. 37, no. 3, pp. 355-361, 1997.

[8] P. Xue, G. M. Xie, B. L. Xiao, Z. Y. Ma, and L. Geng, "Effect of heat input conditions on microstructure and mechanical properties of friction-stir-welded pure copper," Metallurgical and Materials Transactions A, vol. 41, no. 8, pp. 2010-2021, 2010.

[9] H. J. Liu, H. Fujii, M. Maeda, and K. Nogi, “Tensile properties and fracture locations of friction-stir-welded joints of 2017-T351 aluminum alloy," Journal of Materials Processing Technology, vol. 142, no. 3, pp. 692-696, 2003.

[10] T. R. McNelley, S. Swaminathan, and J. Q. Su, "Recrystallization mechanisms during friction stir welding/processing of aluminum alloys," Scripta Materialia, vol. 58, no. 5, pp. 349-354, 2008.

[11] T. Sakthivel and J. Mukhopadhyay, "Microstructure and mechanical properties of friction stir welded copper," Journal of Materials Science, vol. 42, no. 19, pp. 8126-8129, 2007.

[12] R. Nandan, T. DebRoy, and H. K. D. H. Bhadeshia, "Recent advances in friction-stir welding-process, weldment structure and properties," Progress in Materials Science, vol. 53, no. 6, pp. 980-1023, 2008.

[13] J. J. Shen, H. J. Liu, and F. Cui, "Effect of welding speed on microstructure and mechanical properties of friction stir welded copper," Materials and Design, vol. 31, no. 8, pp. 3937$3942,2010$. 